Article

\title{
Associations of Heat-Shock Protein Expression with Meat Quality and Sensory Quality Characteristics in Highly Marbled Longissimus Thoracis Muscle from Hanwoo Steers Categorized by Warner-Bratzler Shear Force Value
}

 \\ Department of Animal Science, Kyungpook National University, 2559 Gyeongsang-daero, Sangju-si, \\ Gyeongsangbuk-do 37224, Korea; eunmi95@knu.ac.kr (E.O.); ananassab@knu.ac.kr (B.L.) \\ * Correspondence: ymchoi1@knu.ac.kr; Tel.: +82-54-530-1232
}

Received: 5 November 2019; Accepted: 2 December 2019; Published: 4 December 2019

\begin{abstract}
The influence of heat-shock protein (HSP) concentrations at $45 \mathrm{~min}$ and $24 \mathrm{~h}$ postmortem on meat quality and sensory quality characteristics of longissimus thoracis muscle from highly marbled Hanwoo steers (beef marbling standard grade 6-8) was investigated. Muscle samples were segregated into three groups based on Warner-Bratzler shear force (WBSF) value. The low group exhibited a lower WBSF value compared to the medium and high groups (37.8 vs. 48.9 and $64.3 \mathrm{~N}, p<0.001$ ). Muscle $\mathrm{pH}$ at $45 \mathrm{~min}$ and $24 \mathrm{~h}$ postmortem was not different $(p>0.05)$, and all groups exhibited low ultimate $\mathrm{pH}$ value $(\mathrm{pH}<5.8)$. Beef steaks from the low group were significantly easier to pierce and chew, and they left less perceptible residue than the high group $(p<0.05)$. These differences in tenderness attributes were associated with differences in small HSPs at 45 min postmortem, with the low group exhibiting a lower level of $\alpha \beta$-crystallin and higher levels of HSP20 and HSP27 compared with the high group $(p<0.05)$. No differences were observed for small HSPs, HSP70, and HSP90 at $24 \mathrm{~h}$ postmortem $(p>0.05)$. Therefore, the expression levels of small HSPs at $45 \mathrm{~min}$ postmortem seems to have the potential to be an indicator of tenderness in highly marbled Hanwoo beef with low ultimate $\mathrm{pH}$.
\end{abstract}

Keywords: heat-shock protein; eating quality; tenderness; highly marbled beef; Hanwoo steers

\section{Introduction}

Heat-shock proteins (HSPs) are well known as molecular chaperones that assist in the normal folding of various polypeptides, help misfolded polypeptides regain their proper configuration, and regulate proteolysis [1,2]. These chaperone properties of HSPs are expressed under a variety of conditions including normal, stressed, and apoptotic, but HSPs do not remain as part of the final protein structure [2]. HSPs are categorized by their functions and molecular weights into distinct families (small HSPs, HSP70, HSP90, etc.), and individual HSPs exhibit different biological functions under apoptotic conditions [2,3]. After exsanguination, muscle fibers convert to an ischemic-anoxic state, and apoptotic cell death occurs before rigor mortis during the conversion of muscle to meat [4]. To maintain cell homeostasis against apoptosis, pro- and anti-apoptotic proteins are released from mitochondria [4]. The levels of HSPs at the early postmortem period are associated with the rate and extent of apoptosis, and they can influence structural and metabolic changes of skeletal muscle during the postmortem period $[4,5]$.

For these reasons, variation in HSP levels associated with apoptosis during the postmortem period can affect the meat quality and sensory quality characteristics, especially the extent of meat 
tenderization $[5,6]$. The protective chaperoning properties of small HSPs, including $\alpha \beta$-crystallin, HSP20, and HSP27, during apoptotic cell death could delay the rate of protein degradation and beef aging [5]. Bernard et al. [7] and Kim et al. [6] reported a negative correlation between the levels of small HSPs and palatability of cooked beef, especially tenderness. Additionally, numerous studies reported inconsistent tenderness of intermediate $\mathrm{pH}$ beef (ultimate $\mathrm{pH}$ ranged between 5.8 and 6.2), and they also suggested that the observed toughness of intermediate $\mathrm{pH}$ beef is associated with higher concentrations of small HSPs [5,8,9]. Yu et al. [10] reported that poor water-holding capacity (WHC) and faster $\mathrm{pH}$ decline in the porcine longissimus dorsi muscle were associated with decreased expression levels of HSP70 and HSP90, as these HSPs play important roles in maintaining the structural network of muscle fiber [11].

Hanwoo steers are known to have a higher intramuscular fat (IMF) content, and the beef tends to exhibit higher sensory quality characteristics, especially tenderness, compared with other breeds such as Holstein steers [12-15]. Inconsistent sensory tenderness is occasionally observed in highly marbled beef, although consumers have high expectations for organoleptic characteristics [14]. The biochemical mechanisms, especially the functions of HSPs during apoptosis, that cause tenderness variation in highly marbled beef are largely unknown. Therefore, the objective of this study was to investigate the relationship between HSP expressions, including $\alpha \beta$-crystallin, HSP20, HSP27, HSP70, and HSP90, and meat quality and sensory quality characteristics of highly marbled Hanwoo steers to identify factors that are associated with tenderness variation in highly marbled beef.

\section{Materials and Methods}

\subsection{Animals and Muscle Sample Preparation}

Hanwoo steers (aged 28-33 months, carcass weight of $466.7 \pm 65.6 \mathrm{~kg}$ ) were transported and slaughtered at the same commercial slaughterhouse in Hoengseong (Korea), and they were randomly selected from a total of 364 highly marbled Hanwoo steers and obtained in three batches $(16,16$, and 17 animals per day; total 49 steers). At $45 \mathrm{~min}$ postmortem, muscle samples (approximately $20 \mathrm{~g}$ per sample) were taken from the longissimus thoracis (LT) muscle at the 13th thoracic vertebra (the standard site of carcass grading in Korea), frozen in liquid nitrogen, and stored at $-80{ }^{\circ} \mathrm{C}$ for Western blot analysis, and muscle $\mathrm{pH}$ was measured directly at the standard site of carcass grading.

At $24 \mathrm{~h}$ postmortem, the carcasses were graded according to the quality grading standard, including marbling, of the Korea Institute of Animal Products Quality Evaluation (KAPE) [16]. Each loin was scored on a nine-point scale (1-9, devoid to very abundant) according to the beef marbling standard (BMS), and highly marbled loin cuts (BMS 6-8) were randomly selected and used for the meat quality and sensory quality measurements. The KAPE provided carcass weight, loin eye area, back-fat thickness, and BMS. After quality grading, samples were collected between the ninth and 13th thoracic vertebrae of the LT muscle, and meat quality measurements including Warner-Bratzler shear force (WBSF) were immediately performed. For analysis of eating quality, each muscle sample was cut into steak-sized chops ( $1.5 \mathrm{~cm}$ thickness, approximately 100 to $120 \mathrm{~g})$, and then immediately frozen and stored at $-20^{\circ} \mathrm{C}$. Additionally, approximately $50 \mathrm{~g}$ samples were taken and stored at $-80{ }^{\circ} \mathrm{C}$ before measuring the IMF concentration and performing Western blot analysis. The IMF content was determined by the Soxhlet method [17] using a solvent extraction system.

\subsection{Warner-Bratzler Shear Force}

WBSF analysis was performed based on a previously published method [18]. Beef samples of approximately $80 \mathrm{~g}$ were individually placed inside a polyethylene bags and heated in a water bath $\left(80^{\circ} \mathrm{C}\right.$ ) until the core temperature reached $71^{\circ} \mathrm{C}$ as measured by a spear-type thermometer (Testo 108 , Testo Inc., Lenzkirch, Germany). For analysis of WBSF, more than 10 replicate cores $(1.27 \mathrm{~cm}$ in diameter) were analyzed by an Instron Universal Testing Machine (Model 1011, Instron Corp., Canton, $\mathrm{OH}, \mathrm{USA}$ ) equipped with a Warner-Bratzler blade operating at a crosshead speed of $200 \mathrm{~mm} / \mathrm{min}$ [19]. 


\subsection{Meat Quality Characteristics}

The muscle $\mathrm{pH}_{45}$ min and $\mathrm{pH}_{24} \mathrm{~h}$ were determined using a portable $\mathrm{pH}$ instrument with a penetration probe (Testo 206-pH2, Testo Inc., Lenzkirch, Germany). Meat surface color was assessed using a Minolta chromometer (CR-400, Minolta Camera Co., Osaka, Japan), which uses diffuse D65 standard illumination and a $0^{\circ}$ viewing angle, on beef loin surfaces after blooming at $4{ }^{\circ} \mathrm{C}$ for $30 \mathrm{~min}$. The lightness $\left(L^{*}\right)$, redness $\left(a^{*}\right)$, and yellowness $\left(b^{*}\right)$ values were expressed as the recommendations of Commission Internationale de l'Eclairage (C.I.E.) [20]. To measure drip loss, muscle samples of approximately $80 \mathrm{~g}$ were put into plastic bags and hung on a net, ensuring that the samples were not in contact with the plastic bag for $48 \mathrm{~h}$ at $4{ }^{\circ} \mathrm{C}$. Percentage of drip loss was calculated as the sample weight change [18]. For measurement of filter-paper fluid uptake (FFU), the filter paper was pre-weighed and placed on the meat surface for less than $2 \mathrm{~s}$ to absorb fluids and then weighed [21]. The cooking loss was also calculated by weighing before and after cooking [18]. Preparation of cooked meat samples for both the WBSF and cooking loss analysis was the same.

\subsection{Sensory Quality Evaluation}

For sensory quality evaluations, a total of 147 beef samples ( 49 muscle samples $\times 3$ replicates) were used during 30 sessions (4-5 loin steaks per session). Eleven trained panelists (six females and five males; 24 to 40 years of age) were used in this study. Approval was granted by the Bioethics Committee of Kyungpook National University (protocol number 2019-0027). Panelist training and sensory quality evaluations were conducted at the Muscle Biology Laboratory of Kyungpook National University under the guidelines of the American Meat Science Association [19] and Meilgaard et al. [22]. The steak samples were thawed at $4{ }^{\circ} \mathrm{C}$ for $24 \mathrm{~h}$ and roasted in a convection oven (MJ324, LG Electronics, Seoul, Korea), which was preheated to $180^{\circ} \mathrm{C}$. The samples were turned every $3 \mathrm{~min}$ and cooked until their core temperatures reached $71^{\circ} \mathrm{C}$, as measured by a thermometer (Testo 108, Testo Inc., Lenzkirch, Germany). Cooked beef was trimmed of surface meat and cut into $1.3 \mathrm{~cm}^{3}$ cubes. Panelists evaluated nine attributes and were instructed to refresh their palate between each tasting with unsalted crackers and water. Scores of tenderness attributes, mouth coating, juiciness, flavor, and off-flavor intensities ranged from 1-9 (low to high) based on previously published procedures [13,19,22].

\subsection{Immunoblotting}

Sarcoplasmic protein was extracted at $45 \mathrm{~min}$ and $24 \mathrm{~h}$ postmortem, according to Pietrzak et al. [23] with slight modifications. The protein concentration was measured by a Bio-Rad protein assay kit (Bio-Rad Laboratories Inc., Richmond, CA, USA) according to the Bradford method [24]. Sarcoplasmic proteins were separated by SDS-PAGE using a Mini-PROTEAN system (Bio-Rad Laboratory Inc., Richmond, CA, USA), transferred to polyvinylidene fluoride (PVDF) membranes (GE Healthcare Ltd., Freiburg, Germany), and blocked with 5\% non-fat dry milk powder in Tris-buffered saline (TBS)/Tween. For Western blot analysis, the primary antibodies used were $\alpha \beta$-crystallin (1:10,000 dilution; ab13496, Abcam Ltd., Cambridge, UK), HSP20 (1:400 dilution; sc-51955, Santa Cruz Biotechnology Inc., Santa Cruz, CA, USA), HSP27 (1:3000 dilution; sc-13132, Santa Cruz Biotechnology Inc., Santa Cruz, CA, USA), HSP70 (1:1000 dilution; SPA-820, StressGen Biotechnology Corp., Victoria, Canada), and HSP90 (1:2000 dilution; SPA-835, StressGen Biotechnology Corp., Victoria, Canada). Secondary antibodies were anti-mouse immunoglobulin G (IgG) horseradish peroxidase (HRP)-linked antibody (1:3000 dilution for $\alpha \beta$-crystallin, HSP20, HSP27, and HSP70; Cell Signaling Technology, Inc., Beverly, MA, USA) and anti-mouse m-IgGk binding protein (BP)/HRP (1:3000 dilution for HSP90; Santa Cruz Biotechnology Inc., Santa Cruz, CA, USA). Proteins were detected with a WesternBright ECL kit (Advansta Inc., Menlo Park, CA, USA) and imaged using an ImageQuant LAS 500 (GE Healthcare Ltd., Freiburg, Germany). Image analysis for each protein band was performed using one-dimensional (1D) image analysis software (Eastman Kodak Co., Rochester, NY, USA). The intensities of protein bands in the same gel were compared, and they were normalized by band intensities of the low group. 


\subsection{Statistical Analysis}

Cluster analysis was conducted using the FASTCLUS procedure of SAS software 9.4 (SAS Institute Inc., Cary, NC, USA) to generate three clusters (low, $n=17$; medium, $n=18$; high, $n=14$ ) based on WBSF value. Normality check was performed by SAS PROC UNIVARIATE. Regarding the WBSF value, BMS, IMF content, carcass traits, meat quality characteristics, and expression levels of HSPs, the general linear model (GLM) procedure was used to elucidate any associations. Regarding the sensory quality characteristics, a GLM was performed to analyze the WBSF value as a fixed effect, while the trained panelists were considered as random effects. Significant differences in the least-square means (LSMs) of investigated parameters between groups were compared by the probability difference option at $p \leq 0.05$. All data were presented as LSMs together with the standard errors.

\section{Results}

\subsection{Comparison of WBSF, BMS, IMF Content, and Carcass Characteristics between WBSF Groups}

Table 1 presents the comparison of WBSF value, BMS, IMF content, and carcass characteristics between groups categorized by WBSF value. As expected, a marked difference was observed in WBSF value of the LT muscle between the groups $(p<0.001)$, and the high group exhibited the highest WBSF value compared with the medium and low groups (64.3 vs. 48.9 and $37.8 \mathrm{~N}$, respectively). There were no significant differences in BMS assessed by trained graders and IMF concentration between the groups $(p>0.05)$. Regarding the carcass characteristics, no differences were observed for carcass weight and loin eye area between the groups, although the high group showed a thinner back-fat value at the 13th thoracic vertebra compared with the low and medium groups (13.8 vs. 18.8 and $19.5 \mathrm{~mm}$, respectively, $p<0.05$ ).

Table 1. Comparison of Warner-Bratzler shear force (WBSF), marbling score, intramuscular fat (IMF) content, and carcass characteristics of the Hanwoo longissimus thoracis muscle in groups categorized by WBSF value.

\begin{tabular}{|c|c|c|c|c|}
\hline & \multicolumn{3}{|c|}{ WBSF Value Group } & \multirow{2}{*}{ Level of Significance $^{1}$} \\
\hline & $\begin{array}{c}\text { Low } \\
(n=17)\end{array}$ & $\begin{array}{c}\text { Medium } \\
(n=18)\end{array}$ & $\begin{array}{c}\text { High } \\
(n=14)\end{array}$ & \\
\hline WBSF (N) & $37.8^{c}(1.04)^{2}$ & $48.9^{b}(0.92)$ & $64.3^{\mathrm{a}}(1.29)$ & $* * *$ \\
\hline Marbling score & $7.76(0.15)$ & $7.34(0.15)$ & $7.29(0.17)$ & NS \\
\hline IMF content $(\%)$ & $20.9(1.35)$ & $19.2(1.01)$ & $19.6(0.96)$ & NS \\
\hline \multicolumn{5}{|l|}{ Carcass characteristics } \\
\hline Carcass weight (kg) & $470(15.8)$ & $480(15.4)$ & $445(17.4)$ & NS \\
\hline Loin eye area $\left(\mathrm{cm}^{2}\right)$ & $103(3.44)$ & $101(3.35)$ & $101(3.79)$ & NS \\
\hline Back-fat thickness (mm) & $18.8^{a}(1.53)$ & $19.5^{\mathrm{a}}(1.48)$ & $13.8^{\mathrm{b}}(1.68)$ & * \\
\hline
\end{tabular}

${ }^{1}$ Level of significance: NS $=$ not significant; ${ }^{*} p<0.05 ;{ }^{* * *} p<0.001$. ${ }^{\mathrm{a}-\mathrm{c}}$ Different superscript letters in the same row represent significant differences $(p<0.05) .{ }^{2}$ Standard error of least-square means.

\subsection{Comparison of Meat and Sensory Quality Characteristics between WBSF Groups}

Beef quality characteristics of the Hanwoo LT muscle for WBSF groups are presented in Table 2. There were no significant differences in muscle $\mathrm{pH}_{45}$ min and $\mathrm{pH}_{24} \mathrm{~h}$ between WBSF groups $(p>0.05)$. Measured meat color, including lightness, redness, and yellowness, also did not differ between the groups $(p>0.05)$. The high group did exhibit a higher cooking loss compared with the low group ( 21.7 vs. $17.1 \%, p<0.05)$, although no differences between the groups were observed in other WHC measurements $(p>0.05)$. 
Table 2. Comparison of meat quality characteristics of the Hanwoo longissimus thoracis muscle in groups categorized by Warner-Bratzler shear force (WBSF) value.

\begin{tabular}{|c|c|c|c|c|}
\hline & \multicolumn{3}{|c|}{ WBSF Value Group } & \multirow{2}{*}{ Level of Significance $^{1}$} \\
\hline & $\begin{array}{c}\text { Low } \\
(n=17)\end{array}$ & $\begin{array}{c}\text { Medium } \\
(n=18)\end{array}$ & $\begin{array}{c}\text { High } \\
(n=14)\end{array}$ & \\
\hline \multicolumn{5}{|l|}{ Muscle $\mathrm{pH}$} \\
\hline Muscle $\mathrm{pH}_{45 \text { min }}$ & $6.52(0.08)^{2}$ & $6.44(0.06)$ & $6.46(0.06)$ & NS \\
\hline Muscle $\mathrm{pH}_{24 \mathrm{~h}}$ & $5.51(0.05)$ & $5.46(0.04)$ & $5.48(0.03)$ & NS \\
\hline \multicolumn{5}{|l|}{ Meat color } \\
\hline Lightness $\left(L^{*}\right)$ & $31.7(1.76)$ & $33.4(1.19)$ & $31.2(1.09)$ & NS \\
\hline Redness $\left(a^{*}\right)$ & $17.0(1.60)$ & $16.5(1.08)$ & $16.6(0.99)$ & NS \\
\hline Yellowness $\left(b^{*}\right)$ & $7.44(1.06)$ & $7.66(0.71)$ & $7.12(0.66)$ & NS \\
\hline \multicolumn{5}{|l|}{ Water-holding capacity } \\
\hline Drip loss (\%) & $1.25(0.38)$ & $0.93(0.28)$ & $1.45(0.26)$ & NS \\
\hline Filter-paper fluid uptake (mg) & $4.35(1.28)$ & $2.81(0.94)$ & $4.65(0.87)$ & NS \\
\hline Cooking loss (\%) & $17.1^{\mathrm{b}}(1.15)$ & $19.9^{\mathrm{ab}}(1.05)$ & $21.7^{\mathrm{a}}(1.48)$ & * \\
\hline
\end{tabular}

\footnotetext{
${ }^{1}$ Level of significance: NS $=$ not significant; ${ }^{*} p<0.05$. ${ }^{\mathrm{a}-\mathrm{b}}$ Different superscript letters in the same row represent significant differences $(p<0.05) .{ }^{2}$ Standard error of least-square means.
}

There were significant differences in all tenderness attributes between WBSF groups (Table 3). A noticeable difference was detected in sensory softness between the groups, and beef samples with a higher WBSF value exhibited a lower softness score compared to beef samples with a lower WBSF value (6.16 vs. $7.49, p<0.001)$. Samples from the high group received lower scores for initial tenderness, chewiness, rate of breakdown, and amount of perceptible residue compared with samples from the medium group $(p<0.05)$. Higher scores of mouth coating (6.97 vs. $6.26, p<0.01)$ and juiciness $(6.69 \mathrm{vs}$. $5.85, p<0.01)$ were observed in the low group compared with the high group. However, no significant differences were observed in flavor and off-flavor intensities between WBSF groups $(p>0.05)$.

Table 3. Comparison of sensory quality characteristics of cooked beef in groups categorized by Warner-Bratzler shear force (WBSF) value.

\begin{tabular}{|c|c|c|c|c|}
\hline & \multicolumn{3}{|c|}{ WBSF Value Group } & \multirow{2}{*}{ Level of Significance $^{1}$} \\
\hline & $\begin{array}{c}\text { Low } \\
(n=17)\end{array}$ & $\begin{array}{l}\text { Medium } \\
(n=18)\end{array}$ & $\begin{array}{c}\text { High } \\
(n=14)\end{array}$ & \\
\hline \multicolumn{5}{|l|}{ Tenderness attributes ${ }^{3}$} \\
\hline Softness & $7.49^{\mathrm{a}}(0.19)^{2}$ & $6.89^{\mathrm{b}}(0.18)$ & $6.16^{c}(0.22)$ & $* * *$ \\
\hline Initial tenderness & $7.11^{\mathrm{a}}(0.20)$ & $6.75^{\mathrm{a}}(0.19)$ & $6.05^{b}(0.24)$ & $* * *$ \\
\hline Chewiness & $6.78^{\mathrm{a}}(0.22)$ & $6.40^{\mathrm{a}}(0.22)$ & $5.85^{\mathrm{b}}(0.27)$ & * \\
\hline Rate of breakdown & $6.67^{\mathrm{a}}(0.19)$ & $6.19^{a}(0.19)$ & $5.35^{\mathrm{b}}(0.23)$ & $* * *$ \\
\hline Amount of perceptible residue & $6.88^{\text {a }}(0.18)$ & $6.53^{\mathrm{a}}(0.17)$ & $5.94^{\mathrm{b}}(0.21)$ & $* *$ \\
\hline Mouth coating & $6.97^{\mathrm{a}}(0.22)$ & $6.34^{\mathrm{b}}(0.21)$ & $6.26^{\mathrm{b}}(0.26)$ & ** \\
\hline Juiciness & $6.69^{\mathrm{a}}(0.19)$ & $6.40^{\mathrm{a}}(0.19)$ & $5.85^{b}(0.23)$ & $* *$ \\
\hline Flavor intensity & $6.49(0.14)$ & $6.31(0.14)$ & $6.06(0.17)$ & NS \\
\hline Off-flavor intensity & $6.92(0.12)$ & $6.67(0.12)$ & $6.63(0.14)$ & NS \\
\hline
\end{tabular}

${ }^{1}$ Level of significance: NS = not significant; ${ }^{*} p<0.05 ;{ }^{* *} p<0.01 ;{ }^{* * *} p<0.001$. ${ }^{\text {a-c }}$ Different superscript letters in the same row represent significant differences $(p<0.05) .{ }^{2}$ Standard error of least-square means. ${ }^{3}$ Score distribution: low to high, softness: hard to soft; initial tenderness: tough to tender; chewiness: very chewy to very tender; rate of breakdown: very slow to very fast; amount of perceptible residue: abundant to none; mouth coating: none to very high; juiciness: not juicy to extremely juicy; flavor intensity: very weak to very strong; off-flavor intensity: very strong to very weak.

\subsection{Comparison of HSP Expression Levels between WBSF Groups}

HSP levels in the LT muscle at the early postmortem period were assessed by Western blot analysis, and the results are graphically shown in Figure 1. The ab13496 antibody specifically reacted with $\alpha \beta$-crystallin in the LT muscle from Hanwoo steers, and expression levels were significantly higher 
in the high group compared with the low and medium groups (2.04 vs. 1.00 and $1.30, p<0.05)$. On the other hand, the high group exhibited lower levels of HSP20 (0.62 vs. 1.00, $p<0.05)$ and HSP27 ( 0.89 vs. $1.00, p<0.05)$ compared to the low group. However, there were no significant differences in the expression levels of HSP70 and HSP90 between WBSF groups ( $p>0.05)$. At $24 \mathrm{~h}$ postmortem, $\alpha \beta$-crystallin and HSP90 were not detected in the LT muscle from the Hanwoo steers (Figure 2). There were no significant differences in the expression levels of HSP20, HSP27, and HSP70 at $24 \mathrm{~h}$ postmortem between WBSF groups $(p>0.05)$.

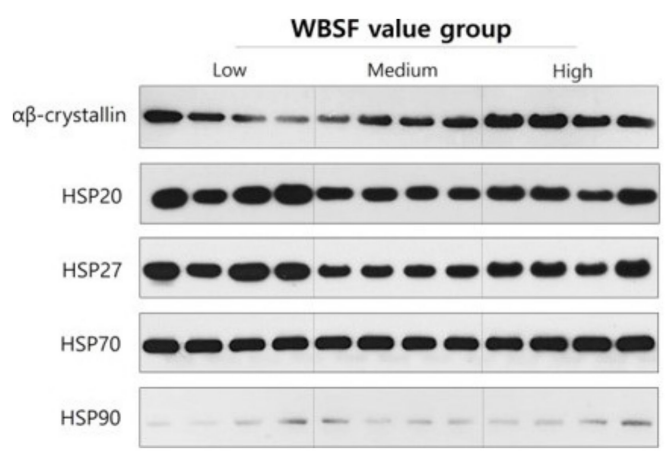

(a) Western blot images



(b) Intensities of HSP at 45 min postmortem

Figure 1. Western blot images (a) and relative intensities (b) of the indicated heat-shock proteins (HSPs) in the Hanwoo longissimus thoracis muscle at $45 \mathrm{~min}$ postmortem for groups categorized by Warner-Bratzler shear force (WBSF) value. Bars indicate standard errors of the means. ${ }^{a-b}$ Different letters denote significant differences $(p<0.05)$.

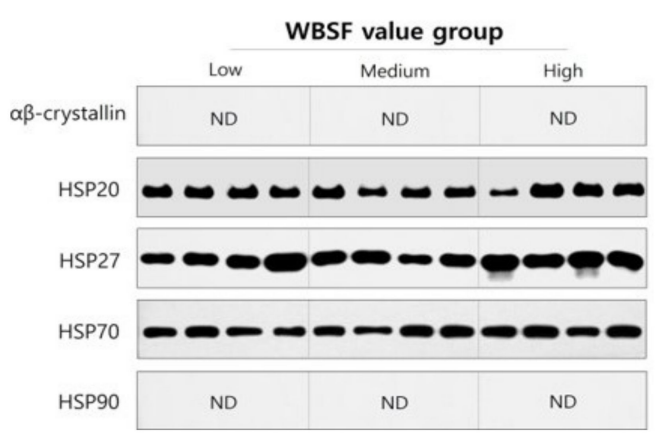

(a) Western blot images
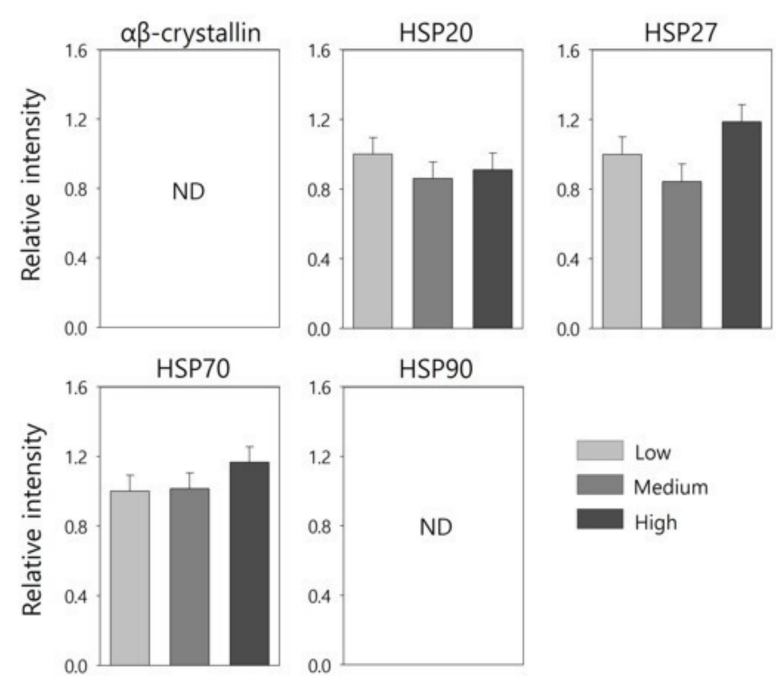

(b) Intensities of HSP at $24 \mathrm{~h}$ postmortem

Figure 2. Western blot images (a) and relative intensities (b) of the indicated heat-shock proteins (HSPs) in the Hanwoo longissimus thoracis muscle at $24 \mathrm{~h}$ postmortem for groups categorized by Warner-Bratzler shear force (WBSF) value. Bars indicate standard errors of the means. ND, not detected. 


\section{Discussion}

Beef palatability, including tenderness, juiciness, and flavor, is one of the most important factors that influence the purchase and repurchase decisions of consumers [25]. In the meat industry, it is important to produce beef with superior eating quality characteristics; it is also important to produce consistently tender beef [25]. Generally, the IMF content or marbling degree is closely associated with the sensory quality characteristics of cooked beef; thus, these characteristics are integral to the beef quality grading systems in the United States, Japan, and Korea [26]. Hanwoo cattle with a higher BMS exhibited more tender, juicy, and flavorful beef compared with cattle with a lower BMS [14,27], and marked differences were also observed in sensory tenderness and WBSF value among the beef quality grades that are primarily based on the BMS [14]. In the current study, BMS and IMF content were similar between the groups categorized by WBSF value, as highly marbled beef loins (BMS 6-8; beef quality grade $1^{+}$to $1^{++}$) were selected. However, significant variation was observed in WBSF value, and beef samples from the low group required less force to pierce the meat sample compared with beef samples from the high group.

Ultimate muscle $\mathrm{pH}\left(\mathrm{pH}_{\mathrm{u}}\right)$ is associated with inconsistent tenderness $[2,5,9]$. Beef with intermediate $\mathrm{pH}_{\mathrm{u}}$ tends to show a higher shear force value compared to beef with high and low $\mathrm{pH}_{\mathrm{u}}$, as less extensive degradation of cytoskeletal proteins and delayed tenderization are observed in beef with intermediate $\mathrm{pH}_{\mathrm{u}}[2,5,9]$. Such intermediate $\mathrm{pH}_{\mathrm{u}}$ beef was frequently observed in bulls due to low-calorie diets and stress before slaughter [9]. However, highly marbled cattle can be obtained through a longer fattening period with a high-protein diet; therefore, the muscle $\mathrm{pH}_{\mathrm{u}}$ of Hanwoo steers was generally lower compared with muscle from cattle that were raised in a pasture-fed production system [14]. In the present study, no muscle samples had intermediate $\mathrm{pH}_{24} \mathrm{~h}$ values; all samples at $24 \mathrm{~h}$ postmortem had low $\mathrm{pH}_{24} \mathrm{~h}$ values $(\mathrm{pH}<5.8)$ (data not shown). Muscle $\mathrm{pH}$ values at $45 \mathrm{~min}$ and $24 \mathrm{~h}$ postmortem were not different between WBSF groups. However, beef with a lower WBSF value exhibited a lower cooking loss compared to beef with a higher WBSF value, as WBSF value was well correlated with cooking loss [18].

There are three aspects to the overall sensation of tenderness: (1) the initial force of teeth penetrating the meat, (2) the ease of fragmentation during chewing, and (3) the amount of perceptible residue after chewing $[28,29]$. Among the sensory tenderness attributes in this study, the first perception of tenderness was related to softness and initial tenderness, the second aspect was associated with chewiness and rate of breakdown, and the third aspect was associated with the amount of perceptible residue $[19,28]$. Thus, the WBSF value as an objective tenderness measurement was more closely associated with the first aspect, especially softness, than the second and third aspects. In this study, there was a significant difference in sensory softness between WBSF groups, although no differences were observed in the other tenderness attributes between the low and medium groups. Moreover, there were no differences in mouth coating and flavor intensity between the medium and high groups.

The first phase in the conversion of muscle into meat is the onset of apoptosis, and the biochemical and structural changes that occur during apoptotic cell death after slaughter influence the beef tenderization processes [2,4]. During apoptotic cell death, $\alpha \beta$-crystallin plays an important role in inhibiting the proteolytic activity of caspase 3, a cysteine peptidase associated with apoptosis [30]. Due to the chaperoning property of $\alpha \beta$-crystallin, an increase in the level of this protein leads to reduced proteolytic degradation of myofibrillar proteins, which means the meat is less tender [7]. Lomiwes et al. [31] reported less degradation of cytoskeletal proteins, including titin and desmin, after adding $\alpha \beta$-crystallin to myofibrillar extracts. These results support the data on $\alpha \beta$-crystallin levels in this study, and beef with lower WBSF values exhibited lower level of $\alpha \beta$-crystallin at $45 \mathrm{~min}$ postmortem compared with beef with higher WBSF values. However, significantly higher levels of HSP20 and HSP27 were observed in the low group compared with the medium and high groups. These higher levels of HSP20 and HSP27 are explained by studies conducted by Morzel et al. [32] and Lomiwes et al. [31], who reported that myofibrillar protein aggregation inhibits protein degradation caused by endogenous proteases, and higher levels of HSP20 and HSP27 prevent the formation of 
aggregated protein complexes. In addition, the chaperone property of HSP20 and HSP27 in the low group may be associated with lower cooking loss compared to the high group. However, the levels of HSP70 and HSP90 at the early postmortem period had a weak association with the WBSF value and palatability of highly marbled Hanwoo steers, although the function of these proteins is to protect muscle fibers from various stressors, including oxidative stress and chemotherapeutic agents [33]. Therefore, the lower level of $\alpha \beta$-crystallin and higher levels of HSP20 and HSP27 at the early postmortem period are associated with lower WBSF value and higher scores of sensory tenderness attributes in highly marbled muscle samples from the low group.

HSPs appear in myofibril within $30 \mathrm{~min}$ of stress being initiated [2,9]. During the postmortem period, as muscle $\mathrm{pH}$ declines to the isoelectric points of individual HSPs, the disappearance of HSPs due to protein precipitation is accelerated, and protein precipitates are transferred from the sarcoplasmic to myofibrillar fraction [9]. The concentrations of these proteins in the sarcoplasmic fraction reach minimum values within $48 \mathrm{~h}$ postmortem [2,9]. Lomiwes et al. [5] suggested that lower shear force values were associated with the precipitation and degradation of small HSPs. In the current study, the disappearance of $\alpha \beta$-crystallin and HSP90 from the sarcoplasmic fraction due to protein degradation was observed at $24 \mathrm{~h}$ postmortem, although the concentrations of HSPs at $24 \mathrm{~h}$ postmortem were not associated with the WBSF value and sensory quality characteristics of highly marbled Hanwoo steer. This result can be explained by a previous study [31], which reported that tenderness of cooked beef was not affected by the amount of HSPs at $24 \mathrm{~h}$ postmortem due to impaired biological functions of these proteins.

\section{Conclusions}

Taken together, lower level of $\alpha \beta$-crystallin and higher levels of HSP20 and HSP27 at $45 \mathrm{~min}$ postmortem were associated with a greater tenderness of cooked beef measured by instrumental and sensory quality evaluations. Therefore, the levels of small HSPs at the early postmortem period can be relevant indicators to explain the tenderness variation in highly marbled LT muscle from Hanwoo steers, which exhibit low $\mathrm{pH}_{24} \mathrm{~h}$.

Author Contributions: Conceptualization, E.O. and Y.M.C.; methodology, E.O., B.L. and Y.M.C.; validation, Y.M.C.; formal analysis, E.O., B.L. and Y.M.C.; investigation, E.O., B.L. and Y.M.C.; resources, E.O., B.L. and Y.M.C.; data curation, E.O., B.L. and Y.M.C.; writing, E.O., B.L. and Y.M.C.; visualization, E.O.; funding acquisition, E.O., B.L. and Y.M.C.; writing-review and editing, E.O., B.L. and Y.M.C.

Funding: This research was funded by the National Research Foundation of Korea (NRF-2017R1D 1A3B03029840).

Acknowledgments: The authors thank the KAPE for their help in the muscle sample collection and quality grading information.

Conflicts of Interest: The authors declare no conflicts of interest.

\section{References}

1. Hartl, F.U.; Hayer-Hartl, M. Molecular chaperones in the cytosol: From nascent chain to folded protein. Science 2002, 295, 1852-1858. [CrossRef]

2. Lomiwes, D.; Farouk, M.M.; Wiklund, E.; Young, O.A. Small heat shock proteins and their role in meat tenderness: A review. Meat Sci. 2014, 96, 26-40. [CrossRef]

3. Arrigo, A.P. In search of the molecular mechanism by which small stress proteins counteract apoptosis during cellular differentiation. J. Cell. Biochem. 2005, 94, 241-246. [CrossRef]

4. Ouali, A.; Gagaoua, M.; Boudida, Y.; Becila, S.; Boudjellal, A.; Herrera-Mendez, C.H.; Sentandreu, M.A. Biomarkers of meat tenderness: Present knowledge and perspectives in regards to our current understanding of the mechanisms involved. Meat Sci. 2013, 95, 854-870. [CrossRef]

5. Lomiwes, D.; Farouk, M.M.; Frost, D.A.; Dobbie, P.M.; Young, O.A. Small heat shock proteins and toughness in intermediate $\mathrm{pH}_{\mathrm{u}}$ beef. Meat Sci. 2013, 95, 472-479. [CrossRef] 
6. Kim, N.K.; Lim, D.; Lee, S.H.; Cho, Y.M.; Park, E.W.; Lee, C.S.; Shin, B.S.; Kim, T.H.; Yoon, D. Heat shock protein $\mathrm{B} 1$ and its regulator genes are negatively correlated with intramuscular fat content in the longissimus thoracis muscle of Hanwoo (Korean cattle) steers. J. Agric. Food Chem. 2011, 59, 5657-5664. [CrossRef]

7. Bernard, C.; Cassar-Malek, I.; Le Cunff, M.; Dubroeucq, H.; Renand, G.; Hocquette, J.F. New indicators of beef sensory quality revealed by expression of specific genes. J. Agric. Food Chem. 2007, 55, 5229-5237. [CrossRef]

8. Balan, P.; Kim, Y.H.B.; Blijenburg, R. Small heat shock protein degradation could be an indicator of the extent of myofibrillar degradation. Meat Sci. 2014, 97, 220-222. [CrossRef]

9. Pulford, D.J.; Dobbie, P.; Fraga Vazquez, S.; Fraser-Smith, E.; Frost, D.A.; Morris, C.A. Variation in bull beef quality due to ultimate muscle $\mathrm{pH}$ is correlated to endopeptidase and small heat shock protein levels. Meat Sci. 2009, 83, 1-9. [CrossRef]

10. Yu, J.; Tang, S.; Bao, E.; Zhang, M.; Hao, Q.; Yue, Z. The effect of transportation on the expression of heat shock proteins and meat quality of M. longissimus dorsi in pigs. Meat Sci. 2009, 83, 474-478. [CrossRef]

11. Picard, B.; Gagaoua, M.; Micol, D.; Cassar-Malek, I.; Hocquette, J.F.; Terlouw, C.E.M. Inverse relationships between biomarkers and beef tenderness according to contractile and metabolic properties of the muscle. J. Agric. Food Chem. 2014, 62, 9808-9818. [CrossRef] [PubMed]

12. Choi, Y.M.; Garcia, L.G.; Lee, K. Correlation of sensory quality characteristics with intramuscular fat content and bundle characteristics in bovine longissimus thoracis muscle. Food Sci. Anim. Resour. 2019, 39, 197-208. [CrossRef] [PubMed]

13. Lee, Y.; Lee, B.; Kim, H.K.; Yun, Y.K.; Kang, S.J.; Kim, K.T.; Kim, B.D.; Kim, E.J.; Choi, Y.M. Sensory quality characteristics with different beef quality grades and surface texture features assessed by dented area and firmness, and the relation to muscle fiber and bundle characteristics. Meat Sci. 2018, 145, 195-201. [CrossRef] [PubMed]

14. Lee, B.; Yoon, S.; Choi, Y.M. Comparison of marbling fleck characteristics between beef marbling grades and its effect on sensory quality characteristics in high-marbled Hanwoo steer. Meat Sci. 2019, 152, 109-115. [CrossRef] [PubMed]

15. Yang, J.; Dashdorj, D.; Hwang, I. Effect of the calpain system on volatile flavor compounds in the beef Longissimus lumborum muscle. Korean J. Food Sci. Anim. Resour. 2018, 38, 515-529. [PubMed]

16. Korea Institute of Animal Products Quality Evaluation. The Beef Carcass Grading. Available online: http://www.ekape.or.kr/index.do (accessed on 1 February 2017).

17. AOAC. Official Methods of Analysis of AOAC International, 19th ed.; AOAC International: Gaithersburg, MD, USA, 2012.

18. Honikel, K.O. Reference methods for the assessment of physical characteristics of meat. Meat Sci. 1998, 49, 447-457. [CrossRef]

19. American Meat Science Association. Research Guidelines for Cookery, Sensory Evaluation, and Instrumental Tenderness Measurements of Fresh Meat; American Meat Science Association: Savoy, IL, USA, 1995.

20. Carter, E.C.; Schanda, J.D.; Hirschler, R.; Jost, S.; Luo, M.R.; Melgosa, M.; Ohno, Y.; Pointer, M.R.; Rich, D.C.; Vienot, F.; et al. Colorimetry, 4th ed.; International Commission on Illumination (C.I.E.): Vienna, Austria, 1 October 2018.

21. Kauffman, R.G.; Eikelenboom, G.; Van der Wal, P.G.; Merkus, G.; Zaar, M. The use of filter paper to estimate drip loss of porcine musculature. Meat Sci. 1986, 18, 191-200. [CrossRef]

22. Meilgaard, M.; Civille, G.V.; Carr, B.T. Sensory Evaluation Techniques, 3rd ed.; CRC Press: New York, NY, USA, 1991; pp. 211-222.

23. Pietrzak, M.; Greaser, M.L.; Sosnicki, A.A. Effect of rapid rigor mortis processes on protein functionality in pectoralis major muscle of domestic turkeys. J. Anim. Sci. 1997, 75, 2106-2116. [CrossRef]

24. Bradford, M.M. A rapid and sensitive method for the quantitation of microgram quantities of protein utilizing the principle of protein-dye binding. Anal. Biochem. 1976, 72, 248-254. [CrossRef]

25. Hocquette, J.F.; Gondret, F.; Baeza, E.; Medale, F.; Jurie, C.; Pethick, D.W. Intramuscular fat content in meat-producing animals: Development, genetic and nutritional control, and identification of putative markers. Animal 2010, 4, 309-319. [CrossRef]

26. Lee, B.; Yoon, S.; Lee, Y.; Oh, E.; Yun, Y.K.; Kim, B.D.; Kuchida, K.; Oh, H.K.; Choe, J.; Choi, Y.M. Comparison of marbling fleck characteristics and objective tenderness parameters with different marbling coarseness within longissimus thoracis muscle with of high-marbled Hanwoo steer. Korean J. Food Sci. Anim. Resour. 2018, 38, 606-614. 
27. Lee, B.; Choi, Y.M. Correlations of marbling fleck characteristics with meat quality and histochemical characteristics in longissimus thoracis muscle of Hanwoo steers. Food Sci. Anim. Resour. 2019, 39, 151-161. [CrossRef]

28. Choe, J.H.; Choi, M.H.; Rhee, M.S.; Kim, B.C. Estimation of sensory pork loin tenderness using Warner-Bratzler shear force and texture profile analysis measurements. Asian Australas. J. Anim. Sci. 2016, 29, 1029-1036. [CrossRef]

29. Lawrie, R.A.; Ledward, D.A. Lawrie's Meat Science, 7th ed.; Woodhead Publishing: Cambridge, UK, 2006.

30. Kamradt, M.C.; Chen, F.; Sam, S.; Cryns, V.L. The small heat shock protein Ab-crystallin negatively regulates apoptosis during myogenic differentiation by inhibiting caspase-3 activation. J. Biol. Chem. 2002, 277, 38731-38736. [CrossRef]

31. Lomiwes, D.; Hurst, S.M.; Dobbie, P.; Frost, D.A.; Hurst, R.D.; Young, O.A.; Farouk, M.M. The protection of bovine skeletal myofibrils from proteolytic damage post mortem by small heat shock proteins. Meat Sci. 2014, 97, 548-557. [CrossRef]

32. Morzel, M.; Terlouw, C.; Chambon, C.; Micol, D.; Picard, B. Muscle proteome and meat eating qualities of longissimus thoracis of Blonde d' Aquitaine young bulls: A central role of HSP27 isoforms. Meat Sci. 2008, 78, 297-304. [CrossRef]

33. Arya, R.; Mallik, M.; Lakhotia, S. Heat shock genes-Integrating cell survival and death. J. Biosci. 2007, 32, 595-610. [CrossRef]

(C) 2019 by the authors. Licensee MDPI, Basel, Switzerland. This article is an open access article distributed under the terms and conditions of the Creative Commons Attribution (CC BY) license (http://creativecommons.org/licenses/by/4.0/). 